\title{
Medicinal herbs as a panacea for biogenic silver nanoparticles
}

\author{
Habeeb Hiba* ${ }^{*}$ and John E. Thoppil
}

\begin{abstract}
Background: Scientists created a new area known as "green nanotechnology" by combining the concept of sustainability with nanotechnology. Its goal is to eliminate the use of chemicals in nanoparticle manufacturing by replacing them with plant-based materials. Green synthesis is promoted as the best alternative to the traditional method of nanoparticle synthesis in this new domain. Plants that constitute a major portion of our biodiversity are embraced with inherent potentiality to be transformed as miracle medicine due to its phytochemicals. These phytochemicals efficiently replace the classical wet chemical ingredients involved in nanoparticle synthesis by upgrading to greener method for its synthesis. By incorporating plant-based sources as the chief ingredient of nanoparticle synthesis, we are able to reduce the hazards of greenhouse gas emissions and enlighten the insights of our scientific community with nanotechnology for green innovation. Hence, this review simultaneously aims at promoting plant extracts as the most efficient as well as renewable recipe for green synthesis of silver nanoparticles and preparing earth for a greener tomorrow.

Methodology: Scientific articles and publications were selected from reputed journals and sorted out with pertinent keywords of this review. Electronic sources like Google Scholar, PubMed, Research Gate, Science Direct, Wiley Online Library, Web of Science and Scopus were searched for potential articles and recent breakthroughs published in the area of silver nanoparticle synthesis via green chemistry and biological methods using plant extracts. Scientific names of medicinal plants were checked using botanical databases like Plant List and International Plant Names Index.

Conclusion: This review pinpoints on empowering better life on earth by protecting it from hazardous effects of conventional nanotechnological production through replacing the former with sustainable green synthesis approach. Ergo, it outlines that by incorporating plant-based sources as the chief ingredient of nanoparticle synthesis, we are able to reduce the hazards of greenhouse gas emissions in turn by slowing down increasing climate change disasters globally and enlighten the insights of our scientific community with nanotechnology for green innovation.
\end{abstract}

Keywords: Green synthesis, Silver nanoparticles, Medicinal plants, Green nanotechnology, Plant extract

\section{Background}

"Both medicinal plants, and a sacred connection to place, heal body, mind, and spirit, and encourage humans to be mindful and loving stewards of the Earth"

Deb Soule

*Correspondence: hiba.vavahaby@gmail.com

Cell and Molecular Biology Division, Department of Botany, University

of Calicut, Malappuram, Kerala, India
From these well-known lines, it is apparent that medicinal plants, with their wondrous potency, frequently enliven our souls with synergetic zeal and maintain a healthy relationship with Mother Nature. To put it another way, we might consider medicinal plants to be a magical recipe that aligns with our aspirations of shaping a better world, which is at the heart of the ideas of sustainable development. The basic definition of sustainable development has been engraved on our minds since infancy, but we have yet to take the promise to adopt it and advocate for it among our peers. 
Nature and its resources have suffered the most in this modern world of increasing disparities created by different anthropogenic actions, either directly or indirectly. We're all aware that nature is frequently referred to be feminine (Mother Nature) due to its great power and dynamic capacity to pour immense care and love on its siblings while simultaneously defeating all sorrow. Mother Nature protects her flora and fauna in the safest possible way. We, as humans, torment this ecosystem to such an extent that we frequently forget about the valuable treasure it hides in its lap. The most valuable treasure is medicinal plants, according to legend.

"Mother nature has the power to please, to comfort, to calm, and to nature one's Soul."

\section{Anthony Williams}

From these well-known phrases, it is apparent that Mother Earth, who nourishes and nurtures all of nature's biotic elements, has an indigenous treasure trove of medicinal plants that serves as a magical potion for her offspring. Because of their ethnopharmacological relevance, medicinal plants are known for their innate healing power. It encompasses a diverse range of plants, from little herbs to enormous trees, all of which are classified into different families within the Kingdom Plantae. Ayurveda, which has produced several therapeutic medicinal concoctions from medicinal plants, has a long history of effective use in Indian culture and tradition. As time goes on, technological advancements have led to the advancement of phytochemical and pharmaceutical sciences, providing us with a thorough understanding of the composition and biological activities of a variety of therapeutic plant products.

Nanotechnology is defined as the contemporary field of research concerned with the design, synthesis, and manipulation of particle structures ranging in size in the region of 1-100 nm (Remya et al. 2017). Nanoparticles are either organic or inorganic based on the constituent employed in its synthesis. The former is carbon based, while latter is noble metal or magnetic type.

Nanoparticles have been incorporated into nascent fields like Herbal and medicinal plant biology, which has resulted in a novel strategy of drug delivery and have been hailed as a magical ingredient in the creation of these magnificent inserts.

According to Kim and Song (2010), the synthesis of nanoparticles using noble metals is being more cosmopolitan among our society due to its inexplicable use in various consumer products ranging from toothpastes, soaps to detergents along with its use in the pharmaceutical industry. Xu et al. (2006) denoted that inorganic nanoparticles are frequently used for drug delivery due to its unique features such as ease of use, good functionality, biocompatibility, ability to get targeted into a specific cell and controlled release of drugs. For decades we are aware that nanoparticles are synthesized by chemical or physical approach. Out of them, the former involves the use of evaporation, condensation and laser ablation, while latter involves the use of reduction in metal ions in solution under conditions favorable for the synthesis of small metal aggregates (Abou El-Nour et al. 2010; Iravani et al. 2014). When looking into silver nanoparticle synthesis, the most popular one is chemical synthesis which sounds to be expensive as well as unfriendly to nature. Hence, the nascent biological approach incorporating phytochemicals from plant-based sources was employed to cover up the discrepancies and enhance its yield (Dawadi et al. 2021).

Green innovation took birth out of the repeated thought process and action plans of scientists.

Plants and its counterparts are extensively used in synthesis of nanoparticles. It is often mediated via intracellular or extracellular means, where latter involving boiling of plant extract or crushing of leaves is the mostly employed type (Rai and Yadav 2013). Further when technology progressed the green route of synthesis was chosen for replacing non-ecofriendly byproducts with eco-friendly ones. This greener route utilizes biotic entities of the environment as its incredible ingredient by altering the classical ingredients in physical and chemical methods of synthesis (Reddy et al. 2012). In other words, for smooth operation of these green route of AgNPs synthesis, the phytochemical composition of the plant extract involved is an inevitable part. Among these, the phytosynthesis of AgNPs was found to be easier than other nanoparticles, namely gold, platinum and palladium nanoparticles. Silver nanoparticles sparkle out among other metallic ones due to its remarkable physiological properties that pertain to the inherent potentiality of silver in our nature, which includes the antibacterial properties of zerovalent silver and the ability of silver salts to easily form zerovalent silver via reduction. In 2020, Lade and Shaneware remarked that formation of silver nanoparticles occurs only when water-soluble components $\left(\mathrm{AgNO}_{3}\right.$, plant-based capping and stabilizing agents-secondary metabolites) are converted into water-insoluble form (nanoparticles). It is believed that during the green synthesis, Ag+ is reduced in a single step reaction to a colored silver sol, which later on due to hyper-reactivity undergoes nucleation and increases in size. As per Balciunaitiene et al. (2021), the phytochemicals like flavonoids and proanthocyanidins are involved in the bioreduction in silver salts by acting as both capping and reducing agents at the same time.

By altering parameters like extract concentration, temperature and $\mathrm{pH}$, size of AgNPs synthesized can be 
regulated. Studies state that extract concentration plays a dual role toward AgNPs size by regulating the presence or absence of capping and reducing agents. Briefly, it can be denoted that former at lower levels cause agglomeration of quasispherical AgNPs, whereas at higher levels results in symmetrical ones. Likewise, temperature possesses a direct relation with growth of AgNPs. Not only that, even polar solvents like methanol and ethanol do control AgNPs size by involving in its preparation and purification (Dawadi et al. 2021).

\section{Review methodology}

This review incorporates scientific literature published in the English language. Several electronic databases such as Google Scholar, PubMed, Web of Science, Research Gate, Springer Link, ScienceDirect and Scopus along with Google search engine were elaborately reviewed for retrieving information on pertinent keywords like green synthesis, medicinal plants, silver nanoparticles, green nanotechnology, respectively. Scientific articles and publications were selected from reputed journals and sorted out for extracting scholarly information on green synthesis of silver nanoparticles from plant-based sources. Scientific names of medicinal plants were checked using botanical databases like Plant List and International Plant Names Index.

A generalized search was further carried out using Google search engine to capture more documents, reports and theses from other reputed sources. The information gathered was saved on personal computers. All papers collected were screened and analyzed by assessing their titles and abstracts.

\section{Main text}

\section{A step toward greener technology}

Green nanotechnology combines the utilization of plant elements with the word green, resulting in a field rich with benefits for safeguarding the safety of life on Earth. As a result, its essential ideals are built on the fundamentals of green chemistry and green engineering (Verma et al. 2019). It was developed as a cleaning technique to eliminate the environmental and human health dangers created by rising nanotechnology production, and to replace them with environmentally friendly manufacturing methods that promote environmental sustainability. Hence, it aims to create nanomaterials that are both cost-effective and energy-efficient by using renewable recipes instead of hazardous ones. This unshakable love and harmony that nanotechnology instills in green chemistry frequently result in an unavoidable partnership that benefits humanity by providing cleaner technologies that commit to adopting a green nano-approach to scientific growth (Schmidt 2007).
Green nanotechnology, according to scientists, is a beneficial application of nanotechnology that reduces costs and dangers while also improving the environment's resilience. Green nanotechnology, more than likely, heralds the dawn of a new age, proclaiming nature's proclivity to eliminate both health and environmental concerns posed by conventional nanomaterials by replacing them with environmentally benign alternatives. As a result, as a corollary principle, it incorporates reduced pollution or waste prevention. Advances in eco-nanotoxicological research support the use of natural resources in the development of nanomaterials as a reliable solution to environmental issues. Green nanotechnology goods are created by combining the essence of aspects such as recycling, energy efficiency, safety, renewable resources, and so on under one roof (Nasrollahzadeh et al. 2019a, b).

The need to embed the goal of sustainable development into the roots of nanotechnology prompted the development of green nanotechnology. Hood (2004) described nanotechnology as an efficient cure for mitigating, preventing, and minimizing harm caused to nature and its fellow beings in 2004. Green nano-manufacturing, according to Dornfeld et al. (2013) is a valuable breakout of technology that can carve out harmless, low-cost, and adaptable nanoproducts without releasing harmful byproducts. The two inseparable aims that underpin the deep core of green nano are process and product, which includes multi-skilled nanomaterials used for renewable energy generation, pollution assessment, environmental remediation, and wastewater purification (Khan 2020).

When nanoscience is combined with green chemistry, it tends to define the latter's sustainability principles. Nano-based solar cells, water treatment, energy storage devices, nanogenerators, thermal energy, and catalysis are among the six primary fields discovered as a result of this research. Green nanotechnology has successfully managed to eliminate fouling and aspires to produce newer harmless ones that are inbuilt with the ability to tackle our current environmental challenges since the beginning of nanomaterial design (Iavicoli et al. 2014). Green chemistry principles, according to Anastas and Kirchhoff (2002), are valuable assets that aid in the expansion of nanotechnology for sustainable development. Green chemistry was born into the scientific world with a strong motive to use chemicals more safely and effectively, according to Andraos (2005).

Green chemistry is defined by Naidu et al. (2008) as "chemistry that can design, develop, and generate chemical products without the risk of producing toxic waste or hazardous end products throughout the entire synthesis." The 12 green chemistry principles emphasize the importance of generating safer, cleaner, and more sustainable nanomaterials that are both environmentally benign and 
biodegradable (Fig. 1). Not only do these tenets focus on lowering hazardous solvent usage, improving product design for end-of-life, and improving energy efficiency and chemical techniques, but they also make it easier to synthesize and process greener and safer nanomaterials (Anastas and Eghbali 2010). Due to intrinsic strengths such as cost-effectiveness, versatility, eco-friendliness, non-toxic nature, and ease of processing, green chemistry has won over other techniques in the quest to protect mother earth and her fellow creatures from the wrathful repercussions of age-old practices (Majeed et al. 2018). This greener way of synthesis is viewed as an undiscovered zone of nanoscience and nanotechnology due to the traditional wet chemical routes for nanoparticle processing, yet it is sensitive to dramatic evolution due to its attitude of creating zero pollution to Mother Nature (Kharissova et al. 2013).

As a result, green chemistry can be said to have a direct and indirect function in the biosphere's ecological equilibrium. According to Fischer and Chan (2007), their main goal is to frame nonhazardous nanomaterials synthesizing techniques as an alternative to toxic ones that cause nanotoxicity difficulties in nature. When nanoparticles are manufactured using environmentally friendly procedures and used in the cleanup process, the term "green" takes on new meaning and value. Furthermore, Ramya and Subapriya (2012) state that biological synthesis methods using plants are the best for green nanomaterial synthesis. Green synthesis is the term for these types of synthesis. Despite being manufactured in a green manner, these nanoparticles are chemically equal in terms of efficacy and other factors. It must lead to the development of a safer version of sustainable nanotechnology as a nature-loving method (Yoshida et al. 2011).

\section{Phytonanotechnology}

\section{"The proper use of science is not to conquer nature but to live in it" \\ Barry Commoner}

From these well-known remarks, it is evident that empirical research should not be used to exploit Mother Nature, but rather to foster a healthy relationship with her. This idea has motivated scientists to develop a better kind of science known as green science, which is based on eco-friendly principles. Green science was developed to foster a close relationship between nature and its offspring. Its central value of healing is strangely linked to the blooming of flowers in the spring. Later on, this cleared the way for the emergence of a new field known as phytonanotechnology, which has an intrinsic desire to comfort nature's lap with its magical flora elixir. It is defined as the use of nanotechnology in plant science and plant production systems to aid in the development of smart crops (Wang et al. 2016a, b).

Phytonanotechnology heralds the start of a new era in which green chemistry and phytonanotechnology are inextricably linked. As a result, it is described as a

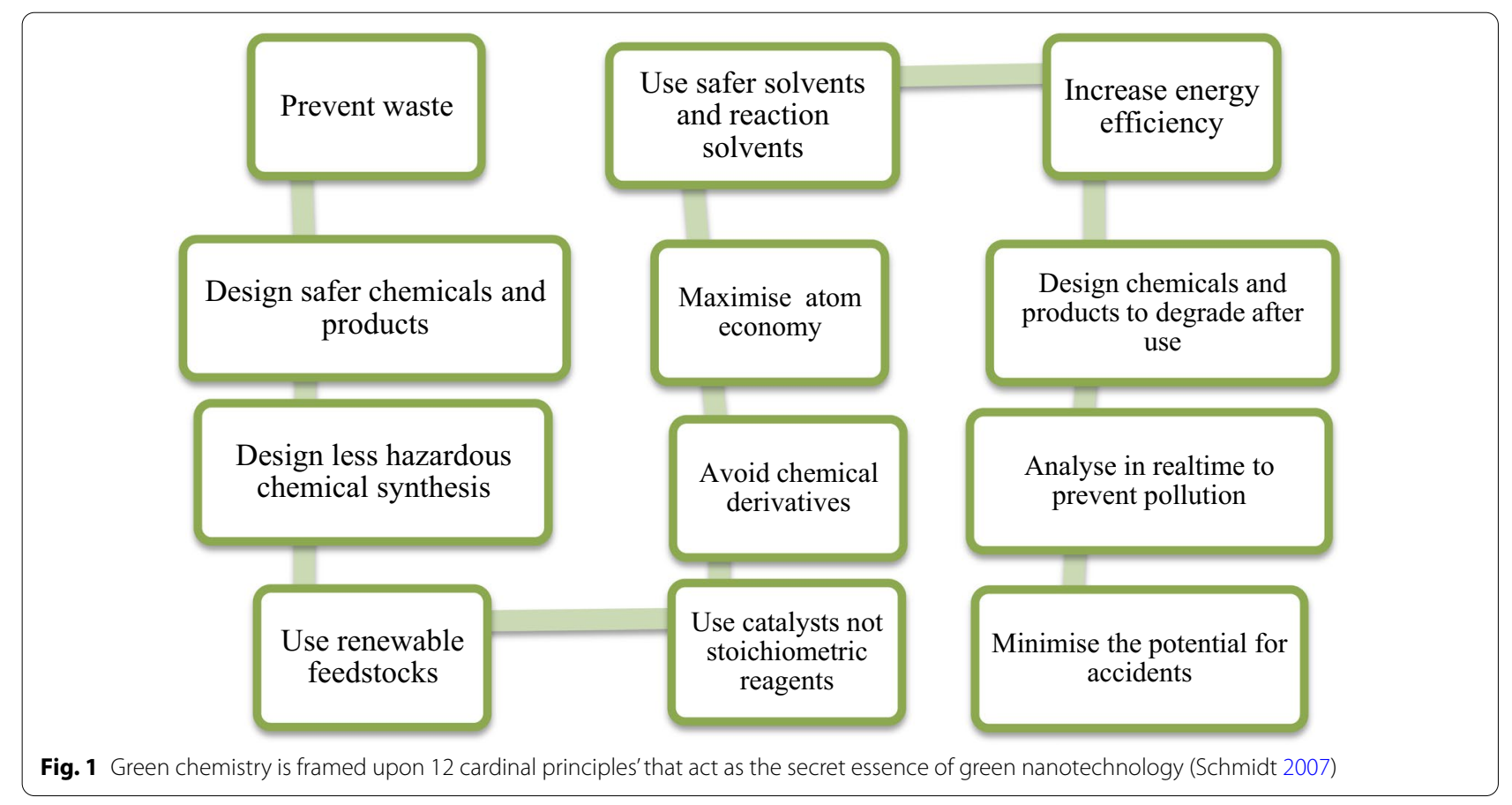


cost-effective and environmentally benign non-conventional plant-based strategy to nanoparticle synthesis that replaces harmful chemicals with non-toxic plant bio-components for achieving long-term production sustainability (Elemike et al. 2020). It also has various advantages over physical and chemical approaches, such as biocompatibility, scalability, simplicity, stability, and environmental friendliness (Karupannan et al. 2020). The emergence of a new method for biologically synthesizing nanoparticles using vitamins, carbohydrates, plant extracts, biodegradable polymers, and microorganisms as reductants and capping agents, which has rekindled hope for a more environmentally sustainable ecosystem. According to Iravani (2011), extracts of plant materials are treated as the best option for stimulating increased nanoparticle synthesis. Green synthesized nanoparticles are considered more advanced than previous methods of synthesis due to their reproducibility, cost-effectiveness, and inherent stability (Kalaiarasi et al. 2010).

Scientists discovered that the green synthesis serves as a cornerstone for this unique technology after delving considerably deeper into its inner core. The biological method to nanoparticle production works in tandem with green synthesis (Fig. 2). It gleams as a first step in the new nanotechnology epic's quest for $100 \%$ sustainability. Green synthesis, according to Duan et al. (2015), is the pioneer stage for designing unique nanomaterials in an eco-friendly method that is non-hazardous to human beings and has the potential to reshape the nanomanufacturing process.

Gawande et al. (2013) said that by taking a more environmentally friendly approach to nanomaterial development, we are indirectly laying the groundwork for the development of both safer and more sustainable nanoproducts that will help to make the world a better place.

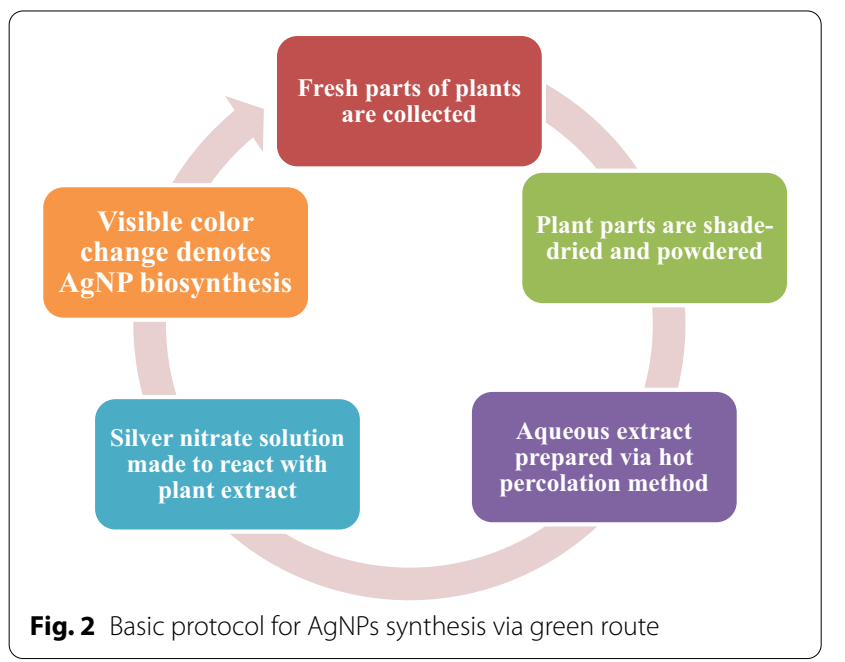

This demonstrates how natural resources are used as adjutants to hazardous synthetic counterparts throughout the process (Kumar et al. 2015).

Due to the considerable benefits it sustains, the biological path chosen for nanoparticle manufacturing appears to be more useful than traditional physical and chemical procedures. The substitution of chemical reducing and capping agents with biological components from the plant-based extract is the most important of them. Secondary metabolites make up the majority of the biological components it contains (phytochemicals). Flavonoids are important in the assembly of nanoparticles because of their antioxidant properties and the free hydrogen generated during the keto-enol conversion process (Jain et al. 2009; Jayaseelan et al. 2011; Jacob et al. 2012), while phenolic acids' antioxidant effectiveness is determined by the metal-chelating activity of their aromatic rings, followed by their biosynthesizing ability. Similarly, alkaloids and organic acids are used as reducing agents in nanoparticle production due to their proclivity for releasing a reactive hydrogen atom and tautomerization of keto-enols (Nishino et al. 1999; Pankhurst et al. 2003; Parial and Pal 2015). They are thought to be involved in the redox reactions that produce nanoparticles from bulk (Vijayakumar 2013; Makarov et al. 2014).

Extracellular or intracellular mechanisms are used to carry out the essential metal ion reduction in the green route of nanoparticle formation. The former allows an aqueous plant extract to interact with the aqueous metal solution, whereas the latter requires interaction with the aqueous metal solution by a living plant or plant biomass. Individual phytochemicals were engineered to react with metal solutions as technology evolved (Dauthal and Mukhopadhyay 2016). Green production of nanoparticles follows the traditional bottom-up method, according to Sangeetha et al. (2011) and Raveendran et al. (2003), which emphasizes oxidation and reduction as the main processes. This technique was described by Ahmed et al. (2016) as atoms self-assembling into nuclei and growing into nanoparticles. Every portion of the plant appears to be a treasure in nanoparticle synthesis since it serves as a substrate for this green synthesis. Leaves, seeds, flowers, fruits, fruit peels, stems, bark, and roots are all part of it (Maniam et al. 2020).

The mechanism to be used during nanoparticle creation via the green approach is still a mystery. The specific process remains unknown since plant bio-components perform the functions of reducing, stabilizing, and capping agents. An intellectual attempt to carve out a deep understanding of the biochemical mechanisms underlying the synthesis of nanoparticles using plantbased materials is to instill a deep understanding of the biochemical mechanisms underlying the synthesis 
of nanoparticles using plant-based materials as a costeffective alternative to traditional methods (Akhtar et al. 2013).

Additionally, the synthesis of nanoparticles can be divided into three stages: activation, growth, and termination (Klaus et al. 1999; Si and Mandal 2007; Kim et al. 2010; Khatoon et al. 2017). During the early phase/activation phase, metal ions are reduced, which is followed by nucleation. To put it another way, the activation phase marks the recouping of metal ions from their parent compound through the influence of biomolecules found in plants, as well as the nucleation of condensed metal ions shortly after the transformation of respective higher oxidation states to zero-valent form (Malik et al. 2014).

Nanoparticles spontaneously aggregate to create larger diameter forms throughout the growing process. A surge in this process frequently triggers the formation of nanotubes, nanorods, and nanotriangles, among other things (Makarov et al. 2014). More precisely, the growth phase entails the amalgamation of metal ions into metal nanoparticles with greater thermodynamic stability, but shape that varies widely. The termination process determines the ultimate structure of nanoparticles. These biosynthesized nanoparticles are embossed to a stable state during the termination stage by capping with plant metabolites (Sajjad et al. 2018). Plant extract's capacity to stabilize metal nanoparticles causes conformational changes in nanoparticles throughout this process. According to Tripathy et al. (2010), the reaction that occurs during synthesis is as follows:

$$
\mathrm{Ag}^{+}+\mathrm{NO}_{3}^{-}+\text {plant extract } \rightarrow \text { AgNPs }+ \text { byproducts. }
$$

Water-soluble components such as $\mathrm{AgNO}_{3}$, plantbased capping and stabilizing agents (secondary metabolites) are converted to water-insoluble form (nanoparticles) during the manufacture of silver nanoparticles (Lade and Shanware 2020a, b).

Silver, gold, platinum, copper, zinc, iron, palladium, and titanium are among the metal nanoparticles obtained by the green approach. Silver nanoparticles are the most common type of nanoparticle. The unusual use of AgNPs as a component of roughly $50 \%$ of nanoproducts is firmly supported by a broad range of scientific papers dating back to 2015 (Gil-Sánchez et al. 2019). Aside from these applications, AgNPs are used in a variety of other fields of science, including catalysis, biomedicine, biological imaging, sensing, photonics, optoelectronics, pharmaceuticals, pollution control, and drug delivery (Ghaedi et al. 2015). This is owing to their inherent characteristics, such as excellent conductivity, chemical stability, and catalytic activity, which endow them with antiviral, antibacterial, antifungal, anti-inflammatory, antiseptic, and biocidal properties (Ahmed et al. 2016).
Greener method for silver nanoparticles synthesis (AgNPs) In today's age of scientific empowerment, an ocean of reports about AgNPs synthesis from plants may be found all over. Mother Earth, which provides a calm haven for an ocean of therapeutic plants, frequently persuades her biological system to work as bio-lab houses for optimal nanoparticle production. Plants and microbes are considered to be biological systems. Plants, which are rich in antioxidants, are frequently used in the production of nanoparticles. Furthermore, by boosting biocompatibility, accessibility, and simplicity of the entire process to be eco-friendly, this green technique allows the use of water as the extraction solvent (Nasrollahzadeh et al. 2019a, b). Green synthesis is a bottom-up technique (Fig. 2) in which biogenic reduction is carried out by extracts of natural compounds that have the intrinsic potential to cap, stabilize, and terminate growth (Hussain et al. 2016). The following is a general outline of how AgNPs are made:

Kingdom Plantae is home to a plethora of medicinal plants with remarkable properties. They play a big role in the green synthesis of AgNPs. The plant extract is a critical substrate for biosynthesis since it contains a number of free radical scavenging chemicals. Plant materials such as flowers, leaves, roots, fruit peels, and other plant parts are used to make plant extract, which can be dried or fresh. The former uses dried powder, whilst the latter uses finely diced plant fragments to ensure thorough extraction. Plant pieces are dried in the sun or in the shade while taking care not to lose their antioxidant value. Extraction is normally done with polar or nonpolar solvents (Mohamad et al. 2014).

According to Tiwari et al. (2011), solvent diffuses into plant tissues during extraction, resulting in the solubilization of molecules with the same polarity. When doing extractions, the solvent used has a direct impact on the amount of reducing agents removed. The plant sample is dispersed into the water and constantly agitated throughout extraction. The best organic solvents for extraction are ethanol and methanol, whereas water is the most appropriate due to its clarity. Even the temperature at which the plants are extracted plays a role in achieving the best yield. At $60-90{ }^{\circ} \mathrm{C}$ the antioxidant level rises to a certain point, but it is degraded as the temperature rises further (Yu et al. 2012; Michiels et al. 2012). Likewise, other factors such as silver nitrate and extract concentrations, light intensity, $\mathrm{pH}$, temperature, and incubation length all have an impact on the success of AgNP synthesis (Akhtar et al. 2013). Various literature searches reveal a slew of scholarly papers on the involvement of $\mathrm{pH}$ in this synthesis. Larger nanoparticles are generated at a pH range of 2 to 4, according to Dubey et al. (2010). Smaller AgNPs are more stable at basic $\mathrm{pH}$ because their 
zeta potential is lower at high acidic $\mathrm{pH}$ than at basic $\mathrm{pH}$. Sathishkumar et al. (2009) discovered that the pH had a significant impact on AgNPs biosynthesized from Cinnamomum zeylanicum Blume powder and bark extract. At acidic pH, ellipsoidal AgNPs develop, but at basic $\mathrm{pH}$, smaller spherical highly scattered AgNPs form. $\mathrm{pH}$, according to Lade and Shaneware (2020a, b), has a significant impact on nanoparticles because of its potential to affect the electrical loads of biomolecules, which alters their efficacy to stabilize, cap, and control their growth. Khatoon et al. (2017) shown that the charge of phytochemicals in plant extracts changes with $\mathrm{pH}$, allowing silver ions to cluster to these molecules. According to Sajjad et al. (2018), pH changes modify the potency to chelate and decrease metal ions, which affects the yield and structure of biosynthesized nanoparticles. Temperature, like $\mathrm{pH}$, has a unique effect in AgNP synthesis, with higher heat boosting yield (Kim et al. 2010).

Apart from demonstrating the effect of $\mathrm{pH}$ on AgNPs, Sathishkumar et al. (2009) also showed that surface plasmon resonance exhibits high absorption peaks in response to a rise in temperature and is connected to nanoparticle size and synthesis speed indirectly. According to Verma and Mehata (2016) uniform AgNPs are generated only when temperature rises in tandem with increased silver ion consumption by high kinetic energy molecules. The time spent on completing the full process of phytosynthesis is known as the incubation or reaction phase. It could be anything from a few minutes to several hours. Secondary metabolites found in the extract are mostly responsible. Lade and Shaneware (2020a, b) later justified this by claiming that the number of secondary metabolites and the time it takes to reduce silver salt have an inverse relationship. Psidium guajava L. took only $90 \mathrm{~s}$ to produce AgNPs with a life span of 18-20 weeks (Raghunandan et al. 2011). After reacting for four hours, AgNPs of Azadirachta indica A. Juss. were created with a four-week life span (Shankar et al. 2004). However, Syzygium aromaticum (L.) Merr. \& L.M.Perry used a longer time period of $24 \mathrm{~h}$ to synthesize silver nanoparticles. Nanoparticle production is influenced by light conditions, whether dark or sunlight. Stable nanoparticles are only created, according to Lade and Patil (2017), when a kinetic reaction between silver salt and functional groups of phytochemicals in the plant extract is triggered by electromagnetic waves of sunlight.

Darkness is chosen as an aid during AgNPs synthesis by Acalypha indica L. leaf extract because light causes photooxidation of silver nitrate. The amount of leaf extract used for synthesis has an impact on the availability of phytochemicals as well as the reduction in silver ions to their stable state, which affects the incubation duration (Lade and Shanware 2020a, b). Similarly, because silver nitrate concentration has a direct link with nanoparticle size, it has a significant impact on nanoparticle creation (Dubey et al. 2010; Dwivedi and Gopal 2010). More exactly, the peak sharpness varies with a rise in absorbance value when the concentration of silver nitrate $(0.25-1 \mathrm{mM})$ is changed (Park 2014).

Biological synthesis is generally carried out in vitro, which is similar to the fundamental green synthesis process. Despite the fact that the reaction takes place at room temperature, the crucial steps are distinguished by the purification of the bio-reducing agent, its mixing with an aqueous metal salt solution, and occasionally by extra heating or stirring (Rajakumar et al. 2012; Sankar et al. 2015). After the nanoparticles have been created, characterization procedures must be used to screen them further. This reveals further information about its distinct characteristics, such as size, shape, crystalline nature, toxicity, and so on. The hue of the mixed solution changes from yellow to dark brown, indicating that AgNPs have been synthesized. Recent research works pinpoint that bioreduction silver to AgNPs is disguised by its respective color change which fluctuates for plants and the synthesis method employed (Uzunuigbe et al. 2020).

According to Abdelmigid et al. (2021), AgNPs formation in pomegranate peel and coffee ground extract was depicted by its respective color variation from pale yellow and brown shades to dark brown. Likewise, in Annona muricata peel extract, the color change observed was from deep yellow to dark brown (Jabir et al. 2021). In other words, it can be stated that whenever a plant extract gets exposed to silver salt solution, AgNPs synthesis initiates along with visible color change. Further, this observation is confirmed by performing a UV-VIS spectroscopy of the colored solution. The resultant solution's Surface Plasmon Resonance (SPR) peaks were later confirmed using UV-VIS spectral analysis. It illustrates the bio-reduction in silver nitrate to silver by interacting with plant extracts and is regarded as the most widely used preliminary characterization approach for AgNPs due to its optical features (Mittal et al. 2012). Peaks in the wavelength range of $200-800 \mathrm{~nm}$, which corresponds to a size range of $2-100 \mathrm{~nm}$, are observed in silver nanoparticles, indicating SPR (Safaepour et al. 2009; Ibrahim 2015). This implies that phytochemicals prevalent in plant extract control the conversion of monovalent silver in silver nitrate to zerovalent AgNPs (Varadavenkatesan et al. 2016). FTIR analysis is also used to learn more about the chemical composition of AgNPs' surface as well as the capping agents involved in their creation. It illustrates the biomolecules that have played a role in the entire synthesis process, including bioreduction and stabilization (Narayanan and Sakthivel 2011a, b, c; Kaviya et al. 2011). Recent studies proclaim that numerous functional groups 
take part in AgNPs fabrication but out of them the most common ones are found to be amide $\left(-\mathrm{CO}-\mathrm{NH}_{2}\right)$, carbonyl $(-\mathrm{CO})$, and hydroxyl $(-\mathrm{OH})$, respectively (Dawadi et al. 2021). AgNPs exhibit a wide array of shapes with its size either less than or greater than $100 \mathrm{~nm}$. In Odontosoria Chinensis, the spherical AgNPs of diameters 22.3-48.2 $\mathrm{nm}$ were found to be fabricated due to the involvements of carboxylic acid and hydroxyl functional groups of terpenoids, tannins, polyphenols and steroids present in it (Johnson et al. 2020). While for Parthenium hysterophorus, spherical AgNPs of size 10.3 $\pm 1.7 \mathrm{~nm}$ were formed due to the bio-reduction silver ion by polypeptides, amine, germinal methyl and hydroxy groups (Sivakumar et al. 2020). Silver nanoparticles synthesized from aqueous bark extract of Picea abies were found to be remarkably large $(100-500 \mathrm{~nm})$ and was due to the participation of aldehydic, carbonyl, and hydroxyl groups of phenols and carboxylic acids in the respective reduction and stabilization, as per the FTIR analysis (Tanase et al. 2020). FTIR spectral analysis of AgNPs biosynthesized from Acacia senegal leaf extract revealed the action of hydroxyl, aromatic and amine groups on its reduction and capping (Uzunuigbe et al. 2020). XRD analysis is also used to reveal the crystalline nature of AgNPs. It displays information on translational symmetry, size, purity, and shape of nanoparticles, as well as phase identification (Sun et al. 2003). Advanced imaging techniques such as SEM-EDAX and TEM are frequently used to gather data on the morphological characteristics of AgNPs as well as their elemental characterization. Zeta potential and Thermal gravimetric analysis (TGA) are used to measure the stability and thermal characteristics of biosynthesized AgNPs. Aside from this, there are a number of approaches for decoding AgNPs in greater depth, but they are frequently underutilized.

\section{Medicinal herbs: an immense ocean for AgNPs synthesis} Plants are preferred over microbes as the most dependable and promising alternatives for AgNPs production since the latter requires the maintenance of certain conditions for optimal synthesis. Plants that are known to be medicinal are found in almost every family. When we go deeper into our everyday routines, we may discover that our lives are entwined with a diverse range of plants, each with its own set of capabilities. It is at ease due to an old habit of incorporating folk herbal treatment into daily life. The 10 sacred flowers, also known as "Dasapushpam," are one such well-known example. It includes Aerva lanata, Biophytum sensitivum, Curculigo orchioides, Cyanthillium cinereum, Eclipta alba, Evolvulus alsinoides, Ipomea sepiaria, Emilia sonchifolia, Cardiospermum halicacabums, and Eclipta alba, Evolvulus alsinoides, Eclipta alba, Evolvulus alsinoides. The therapeutic powers of these miracle herbs have been noted in medicinal biology. Dasapushpam is said to depict the cultural and artistic components of Kerala's tradition, according to Varghese et al. (2010). Kerala's Western Ghats have embraced their tenacity for centuries.

Instilling a practice of manufacturing silver nanoparticles from their medicinally useful part would bring a new insight to pharmacology in terms of improving medication delivery efficacy. As a result, scientists are working hard to biosynthesize AgNPs from plants in an environmentally acceptable and sustainable manner. Our current literature collection includes a number of reports on such synthesis, as shown below. Silver nanoparticles made from Aerva lanata flower extract were discovered to have cytotoxicity against HeLa cells as well as antibacterial efficacy against Klebsiella planticola. These AgNPs predicted an SPR peak at $460 \mathrm{~nm}$ and were found to be polydispersed with a nanoscale size of $95 \mathrm{~nm}$ after TEM and SEM investigation. Its FTIR research demonstrated that carboxylic acids and secondary amines operate as bio-reducing agents in the flower extract (Kanniah et al. 2020). Its leaves, like flowers, were used to synthesize AgNPs via microwave irradiation and were discovered to be predominantly spherical with an average size of $18.62 \mathrm{~nm}$ (Joseph and Mathew 2015). Despite this, a complete extract of the plant was used to make spherical AgNPs with antibacterial activity that were $50 \mathrm{~nm}$ in size. It has an absorbance peak at $430 \mathrm{~nm}$, according to its UV-VIS spectral analysis (Appapalam and Panchamoorthy 2017). The AgNPs discovered from leaf extract of Biophytum sensitivum were found to be well dispersed spherical ones with a diameter of $8 \mathrm{~nm}$, and their SPR peak was detected at $460 \mathrm{~nm}$ (Kavitha et al. 2021). Joseph et al. attempted to manufacture AgNPs from B.sensitivum by microwave-assisted green synthesis in 2015 , and were able to get nanoparticles with a diameter of $19.06 \mathrm{~nm}$, as observed by TEM. AgNPs are synthesized in Curculigo orchioides using the leaf, root, and rhizome. Venkatachalam et al. (2017) used two types of extracts, namely boiling and grinding, to carry out the green synthesis of AgNPs. Using UV-VIS spectral analysis, silver nanoparticles from the former extract had a peak at $433 \mathrm{~nm}$, whereas those from the latter had a peak at $443 \mathrm{~nm}$. AgNPs were found to be spherical with a size of 5-17 nm using FESEM and HRTEM imaging. OH groupcontaining chemicals are used as both capping and stabilizing agents in this nanosynthesis. Due to its larvicidal, antibacterial, and anticancer properties, silver nanoparticles of size 15-18 $\mathrm{nm}$ were also generated from its rhizome by boiled extract, which might be molded into a potential medication (Kayalvizhi et al. 2016). Similarly, Saha et al. (2016) conducted an experiment in 2016 to optimize parameters for successful AgNP synthesis. 
She demonstrated that mono-dispersed spherical AgNPs may be produced easily using $2 \mathrm{mM} \mathrm{AgNO}{ }_{3}, 20 \%$ rhizome extract, $\mathrm{pH} 8$, and $60^{\circ} \mathrm{C}$. The size of the AgNPs obtained ranged from 5 to $28 \mathrm{~nm}$, with an SPR peak at $430 \mathrm{~nm}$. Recently, in 2018, the dried roots of C. orchioides were used to produce crystalline spherical AgNPs with an average size of $50-70 \mathrm{~nm}$ and an SPR band at $440 \mathrm{~nm}$ after a 40-min incubation period (Dave 2018). According to recent sources, Vernonia cinerea has undergone taxonomic renaming and is now known as Cyanthillium cinereum. This plant's use in the biosynthesis of AgNPs dates back much before this revision. Sahayaraj et al. (2015) produced polydisperse crystalline AgNPs in the size range of 5-50 $\mathrm{nm}$, which they discovered using SEM and XRD investigation in 2014. The role of gallic acid and glucose in the decrease and stability of AgNPs at basic $\mathrm{pH}$ was also revealed using FTIR research (Sivaraman et al. 2009). Not only that, but these AgNPs were found to be an effective antimicrobial agent against the bacteria Xanthomonas campestris pv. malvacearum, which causes bacterial blight in cotton plants. Ramaswamy et al. (2015) employed the whole plant extract for green synthesis later in 2015. By treating 5\% plant extract with $1 \mathrm{mM}$ $\mathrm{AgNO}_{3}$ at $\mathrm{pH} 6$ for $1 \mathrm{~h}$ at $50{ }^{\circ} \mathrm{C}$, they were able to get the highest yield. Based on the concentrations of extract and silver nitrate at $\mathrm{pH} 6$, the SPR band varied between 400 and $450 \mathrm{~nm}$. Within the size range of $40-75 \mathrm{~nm}$, the nanoparticles produced were predominantly spherical, polydispersed, and slightly aggregated. Zani et al. (2016) demonstrated that AgNPs biosynthesized from its leaf extract are the most effective anticancer drug for treating a cell line with acute myeloid leukemia. These nanoparticles were made by combining plant extract with salt solution in three different ratios (1:5, 1:10, and 1:20), and they were discovered to be spherical and $15.92 \mathrm{~nm}$ in size. AgNPs synthesis was mediated by leaf extract in the grass Cynodon dactylon. In 2011, Lokina and Stephen (2011) conducted an attempt, which resulted in the creation of spherical and face-centered cubic AgNPs with particle sizes ranging from 5 to $25 \mathrm{~nm}$. Later that year, Sahu et al. (2013) used sunlight as a catalyst to synthesis AgNPs from leaf extract with an average size of 8-10 nm. Supraja et al. (2013) also synthesized AgNPs in 2013 by conducting optimization tests with extracts generated using various procedures. The highest yield was found in homogenized plant extract exposed to sunshine irradiation (Rastogi and Arunachalam 2011), which was supported by the presence of a prominent SPR peak at $450 \mathrm{~nm}$. The size range of the AgNPs that resulted was within the range.

Eclipta alba silver nanoparticles were made by combining its leaf extract with a $1 \mathrm{mM} \mathrm{AgNO}_{3}$ solution in a 1:9 ratio over the course of $30 \mathrm{~min}$. SEM investigation revealed that the resulting AgNPs had a face-centered cubic shape with particles in the 310-400 $\mathrm{nm}$ size range (Premasudha et al. 2015). Suma and Navyashree (2018) succeeded in creating spherical AgNPs endowed with excellent antibacterial activity at a size of $5.8 \mathrm{~mm}$ by allowing Emilia sonchifolia leaf extract to react with $1 \mathrm{mM}$ silver nitrate solution at $30^{\circ} \mathrm{C}$ for $48 \mathrm{~h}$. Ipomea sepiaria is an untapped prospective candidate in the field of green nanotechnology since it has the ability to fight cancer. Several additional related species in the Ipomea genus are widely used to biosynthesize AgNPs using green synthesis. The interaction of Evolvulus alsinoides leaf extract with $1 \mathrm{mM} \mathrm{AgNO}$ was used to attempt green synthesis of AgNPs. The produced AgNPs were spherical and ranged in size from 50 to $75 \mathrm{~nm}$, exhibiting a monocrystalline phase with a face-centered cubic structure (Anbarasu et al. 2016). Previously, polydispersed spherical AgNPs with a diameter of 37-47 nm were attempted to be made by combining aqueous leaf extract and silver nitrate solution $(1 \mathrm{mM})$ in a 1:9 ratio, then incubating at $37^{\circ} \mathrm{C}$ for $24 \mathrm{~h}$ with continuous stirring at $1000 \mathrm{rpm}$ (Arun Kumar et al. 2014). Shekhawat et al. (2013) began working on AgNP biogenesis from Cardiospermum halicacabum in 2013 by modifying the leaf extract and silver nitrate solution to react in 1:9 proportions. The visible color associated with the creation of AgNPs was visible after $25 \mathrm{~min}$ of shaking, and its intensity increased over the course of the $12 \mathrm{~h}$ incubation period. Sundararajan et al. (2016), on the other hand, found that AgNPs were generated after 30 min of mixing followed by $16 \mathrm{~h}$ of incubation, and that their production was maximized. These bio-AgNPs had an average crystal size of $23 \mathrm{~nm}$, with a spherical shape and face-centered cubic crystal structure.

A collection of publications on nanoparticle creation by green synthesis has just been published in nanoscience. Their AgNPs production by green approach appears to be a potential arena of research due to their nutraceutical, pharmacological, and ethnobotanical relevance. The synthesis of AgNPs is aided by the use of several ayurvedic plants and their formulations. "Triphala," a well-known ayurveda compound, is utilized as a multifunctional cure for a variety of human illnesses. It's made up of Phyllanthus emblica, Terminalia bellirica and Terminalia chebula fruits, all of which have medicinal properties. Each of these fruits is used to make silver nanoparticles using a biological technique.

The fruit of Phyllanthus emblica is used to produce an aqueous extract for the synthesis. Renuka et al. (2020) generated hexagonal AgNPs with an average crystal size of $30 \mathrm{~nm}$ and a face-centered cubic lattice in 2020. These nanoparticles were also found to be efficient against Klebsiella pneumoniae and 
Table 1 Biosynthesis of AgNPs from different plants parts with its respective size and shape

\begin{tabular}{|c|c|c|c|c|c|}
\hline S. no & Name of plant & Plant part used & Shape & Size $(\mathrm{nm})$ & Reference \\
\hline 1 & Aegle marmelos & $\begin{array}{l}\text { Leaves } \\
\text { Fruit }\end{array}$ & Spherical & $\begin{array}{l}60 \\
159-181\end{array}$ & $\begin{array}{l}\text { Rao and Paria (2013) } \\
\text { Devi et al. (2020) }\end{array}$ \\
\hline 2 & Acorus calamus & Rhizome & Spherical & 31.83 & Nakkala et al. (2014) \\
\hline 3 & Asparagus racemosus & $\begin{array}{l}\text { Roots } \\
\text { Leaves }\end{array}$ & Spherical & $\begin{array}{l}30-50 \\
5-15\end{array}$ & $\begin{array}{l}\text { Khanra et al. (2016) } \\
\text { Satyanarayana et al. (2020) }\end{array}$ \\
\hline 4 & Boerhaavia diffusa & Whole plant & Spherical & 25 & Kumar et al. (2014) \\
\hline 5 & Aristolochia indica & Leaves & Spherical/cubical & $30-55$ & Murugan et al. (2015) \\
\hline 6 & Moringa oleifera & Leaves & Rectangle & 11 & Nayak et al. (2015) \\
\hline 7 & Justicia adhathoda & Leaves & Spherical & $5-50$ & Bose and Chatterjee (2015) \\
\hline 8 & Abutilon indicum & Leaves & Crystalline & 106 & Prathap et al. (2014) \\
\hline 9 & Hemidesmus indicus & Leaves & Spherical & 25.24 & Latha et al. (2015) \\
\hline 10 & Calotropis gigantea & Latex & Spherical & $5-30$ & Rajkuberan et al. (2015) \\
\hline 11 & Centella asiatica & Leaves & Spherical & $30-50$ & Rout et al. (2013) \\
\hline 12 & Tribulus terrestris & Fruit & Spherical & $16-28$ & Gopinath et al. (2012) \\
\hline 13 & Aloevera & Leaves & Spherical, triangular & $50-350$ & Chandran et al. (2006) \\
\hline 14 & Ocimum tenuiflorum & Leaves & Cuboidal & 50 & Banerjee et al. (2014) \\
\hline 15 & Eucalyptus hybrida & Leaves & Crystalline, spherical & $50-150$ & Dubey et al. (2009) \\
\hline 16 & Euphorbia hirta & Leaves & Spherical & $40-50$ & Elumalai et al. (2010) \\
\hline 17 & Catharanthus rosesus & Leaves & Spherical & $27-30$ & Kotakadi et al. (2013) \\
\hline 18 & Gloriosa superba & Leaves & Triangular & 20 & Gopinath et al.(2016) \\
\hline 19 & Piper logum & Fruits & Spherical & $17.6-41$ & Jacob et al. (2012) \\
\hline 20 & Piper nigrum & Fruits & Spherical & $32-100$ & Mohapatra et al. (2015) \\
\hline 21 & Plectranthus amboinicus & Leaves & Spherical & 18 & Ajitha et al. (2014) \\
\hline 22 & Pistacia atlantica & Seeds & Spherical & $10-50$ & Sadeghi et al. (2015) \\
\hline 23 & Lansiumdomesticum & Fruit peel & Spherical & $10-30$ & Shankar et al. (2014) \\
\hline 24 & Solanum xanthocarpum & Fruit & Spherical & 10 & Amin et al. (2012) \\
\hline 25 & Zingiber officinale & Rhizomes & Spherical & 10 & Singh et al. (2011) \\
\hline 26 & Alstonia scholaris & Bark & Spherical & 50 & Shetty et al. (2014) \\
\hline 27 & Tinospora cordifolia & Leaves & Spherical & 30 & Selvam et al. (2017) \\
\hline 28 & Morinda citrifolia & Roots & Spherical & $30-55$ & Suman et al. (2013) \\
\hline 29 & Tephrosia tinctoria & Stem & Spherical & 73 & Rajaram et al. (2015) \\
\hline 30 & Allium sativum & Leaves & Spherical & $4-22$ & Ahamed et al. (2011) \\
\hline
\end{tabular}

Staphylococcus aureus bacterium strains. Terminalia chebula leaf and fruit extracts are used to make silver nanoparticles. Edison and Sethuraman (2012) made AgNPs from its fruit extract in 2012 by combining $1 \mathrm{ml}$ of it with $25 \mathrm{ml}$ of $0.01 \mathrm{M}$ silver nitrate at room temperature. They were able to observe the stability of nanoparticles as they were elevated to a $\mathrm{pH}$ of neutral. AgNPs were discovered to be crystalline with a size of roughly $25 \mathrm{~nm}$ and to have catalytic activity toward dye degradation via the electron relay effect during characterization. Espenti et al. (2016) used T. chebula leaf extract for a study. They made the synthesis by combining leaf extract with $0.01 \mathrm{M} \mathrm{AgNO}_{3}$ and shaking it for half an hour at $100 \mathrm{rpm}$ at room temperature. The resulting nanoparticles were uniformly scattered spherical nanoparticles with an average diameter of $60 \mathrm{~nm}$.
AgNPs are biosynthesized by Terminalia bellirica using its fruit and kernel extract. Patil et al. (2017) produced biogenic AgNPs in 2017 by combining its aqueous fruit extract with $3 \mathrm{mM} \mathrm{AgNO}$ and microwave irradiating the mixture. The AgNPs generated were practically sphere-shaped with a size of $20.6 \mathrm{~nm}$ and were examined for antibacterial and antibiofilm efficacy, ensuring its use as a nanocatalyst in the nanomedical industry. Sharma (2021) stated in 2021 that AgNPs may also be made from an ethanolic extract of its fruits. In addition to these reports, the well-known formulation "Triphala" is also employed for green manufacture of silver nanocolloids. These were designed with the goal of enhancing the synergistic effect of silver and extract when used together to treat human illnesses. Triphala extract was mixed in 1:2 with $1 \mathrm{mM}$ silver nitrate solution, 
then microwave irradiated for $2-5 \mathrm{~min}$ to form nanocolloids. UV-VIS spectrum studies supported its development. It has an average size of $242.2 \mathrm{~nm}$, according to characterization (Ranjani et al. 2019). In addition to these publications, green synthesis of silver nanoparticles was carried out in a variety of other plants under ideal conditions, using plant parts such as seed, fruit and its peel, stem, bark, and latex.

The oil-producing plant Jatropha curcas, which has natural therapeutic properties, synthesizes AgNPs via the green method by employing its latex and seed extract. Silver nanoparticles generated from its aqueous seed extract had a diameter of $15-50 \mathrm{~nm}$ and a radius of $10-20 \mathrm{~nm}$, whereas those synthesized from its latex had a radius of 10-20 nm (Bar et al. 2009a,b).

The manufacturing of nanoparticles is a never-ending process. This is backed up by the valuable medicinal plant treasure trove found in our forest land. Due to the amazing potentialities, these plants continue to add reports relevant to AgNPs synthesis (Table 1) they promise connected sectors of nanoscience such as nanomedicine and nanopharmacology. The biosynthesis of green silver nanoparticles from diverse plant sources is therefore listed and depicted below (Table 1).

In a word, humans would never have been able to establish a nascent technology for manufacturing nanoparticles without the presence of plants in the biosphere. In other terms, it can be defined as a healthy partnership in which plant sources and nanosynthesis are intertwined, allowing nanotechnology to be empowered for sustainable growth.

\section{Conclusions}

Scientists can establish the notion of "green nano" by combining sustainability into nanosynthesis, which has paved the way for green route nanoparticle synthesis. In a nutshell, this new approach is dubbed "green nanotechnology," because it is based on green chemistry. It promotes an environmentally benign and cost-effective method of producing nanomaterials, ensuring a future world with a much safer ecosystem. Furthermore, scientists' efforts to create silver nanoparticles in order to protect people's lives will prove to be a blessing in disguise in the coming years. Plants are the main element in sustainable nanosynthesis, which ensures the earth's well-being. Plants are frequently regarded as the center of gravity in our existence, as they are solemnized as the elixir of life by pioneering green synthesis of silver nanoparticles. Since the last era, plant extracts' powerful decreasing and capping abilities have broadened the scope and literature efforts in this area. Our planet is endowed with a vast array of mystical plants that can both flourish and nourish our life. However, because of our inborn need for a lavish lifestyle, we frequently overlook them, making survival in the biosphere the most difficult. We willfully forget our commitment to nature in our desire to instill an affluent lifestyle. Scientists have been driven to carve out a safer form of nanotechnology based on the traditional concept of sustainable development as a result of this mindset. Such efforts have not only made life easier, but they have also sparked greater research in this area, allowing the creation of compounds that aid in functionalization.

\section{Abbreviations}

AgNPs: Silver nanoparticles; SPR: Surface plasmon resonance; UV-VIS: Ultraviolet-visible; FTIR: Fourier-transform infrared spectroscopy; XRD: X-ray diffraction; TEM: Transmission electron microscopy; SEM: Scanning electron microscopy; EDAX: Energy-dispersive X-ray analysis; TGA: Thermogravimetric analysis; $\mathrm{AgNO}_{3}$ : Silver nitrate.

\section{Acknowledgements}

Not applicable.

\section{Authors' contributions}

$\mathrm{HH}$ gathered and processed the literature collected, drafted the manuscript and designed the figures. JET provided critical feedback, shaped the manuscript and proofread it. All authors have read and approved the manuscript.

\section{Funding}

There are currently no funding sources in the design, collection and analysis of study.

Availability of data and materials

Not applicable.

\section{Declarations}

Ethics approval and consent to participate

Not applicable.

Consent for publication

Not applicable.

Competing interests

The authors declare that they have no competing interests.

Received: 29 October 2021 Accepted: 26 December 2021

Published online: 15 January 2022

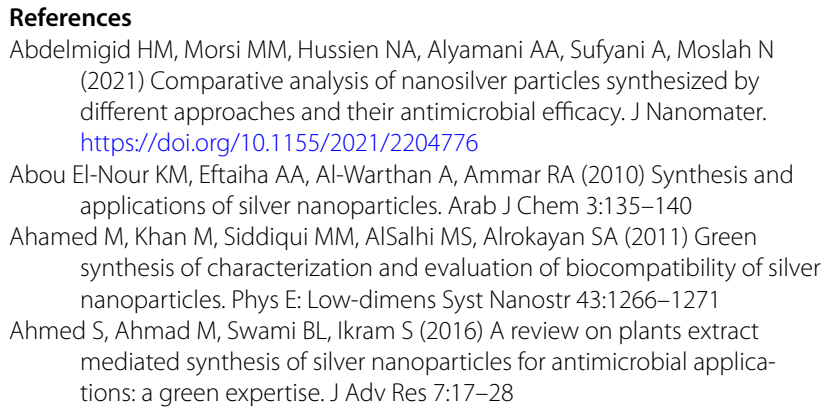

Abdelmigid HM, Morsi MM, Hussien NA, Alyamani AA, Sufyani A, Moslah N (2021) Comparative analysis of nanosilver particles synthesized by different approaches and their antimicrobial efficacy. J Nanomater. https://doi.org/10.1155/2021/2204776

Abou El-Nour KM, Eftaiha AA, Al-Warthan A, Ammar RA (2010) Synthesis and applications of silver nanoparticles. Arab J Chem 3:135-140

Ahamed M, Khan M, Siddiqui MM, AlSalhi MS, Alrokayan SA (2011) Green synthesis of characterization and evaluation of biocompatibility of silver nanoparticles. Phys E: Low-dimens Syst Nanostr 43:1266-1271

Ahmed S, Ahmad M, Swami BL, Ikram S (2016) A review on plants extract mediated synthesis of silver nanoparticles for antimicrobial applications: a green expertise. J Adv Res 7:17-28 
Ajitha B, Reddy Y, Reddy P (2014) Biosynthesis of silver nanoparticles using Plectranthus amboinicus leaf extract and its antimicrobial activity. Spectrochim Acta A Mol Biomol Spectrosc 128:257-262

Akhtar M, Panwar J, Yun Y (2013) Biogenic synthesis of metallic nanoparticles by plant extracts. ACS Sustain Chem Eng 1:591-602

Amin M, Anwar F, Janjua M, lqbal M, Rashid U (2012) Green synthesis of silver nanoparticles through reduction with Solanum xanthocarpum L. berry extract: characterization, antimicrobial and urease inhibitory activities against Helicobacter pylori. Int J Mol Sci 13:9923-9941

Anastas P, Eghbali N (2010) Green chemistry: principles and practice. Chem Soc Rev 39:301-312

Anastas P, Kirchhoff M (2002) Origins, current status, and future challenges of green chemistry. Acc Chem Res 35:686-694

Anbarasu R, Selvan G, Baskar S, Raja V (2016) Pharmacological potential of silver nanoparticles (AgNPs) derived from Evolvulus alsinoides. Int J Recent Res Appl Stud 3:30-38

Andraos J (2005) Unification of reaction metrics for green chemistry: applications to reaction analysis. Org Process Res Dev 9:149-163

Appapalam S, Panchamoorthy R (2017) Aerva lanata mediated phytofabrication of silver nanoparticles and evaluation of their antibacterial activity against wound associated bacteria. J Taiwan Inst Chem Eng 78:539-551

Arun Kumar M, Safana Farjeen M, Divya SK, Jeyadoss T (2014) Quorum quenching and antibacterial activity of silver nanoparticles synthesized from medicinal plants against methicillin-resistant Staphylococcus aureus (MRSA). Int J Pharm Pharm Sci 6:358-362

Balciunaitiene A, Viskelis P, Viskelis J, Streimikyte P, Liaudanskas M, Bartkiene E, Lele V (2021) Green synthesis of silver nanoparticles using extract of Artemisia absinthium L., Humulus lupulus L. and Thymus vulgaris L., physico-chemical characterization, antimicrobial and antioxidant activity. Processes 9:1304

Banerjee P, Satapathy M, Mukhopahayay A, Das P (2014) Leaf extract mediated green synthesis of silver nanoparticles from widely available Indian plants: synthesis, characterization, antimicrobial property and toxicity analysis. Bioresour Bioprocess 1:1-10

Bar H, Bhui D, Sahoo G, Sarkar P, De S, Misra A (2009a) Green synthesis of silver nanoparticles using latex of Jatropha curcas. Colloids Sur a: Physicoch Eng Asp 339:134-139

Bar H, Bhui D, Sahoo G, Sarkar P, Pyne S, Misra A (2009b) Green synthesis of silver nanoparticles using seed extract of Jatropha curcas. Colloids Sur a: Physicoch Eng Asp 348:212-216

Bose D, Chatterjee S (2015) Antibacterial activity of green synthesized silver nanoparticles using Vasaka (Justicia adhatoda L.) leaf extract. Indian J Microbiol 55:163-167

Chandran S, Chaudhary M, Pasricha R, Ahmad A, Sastry M (2006) Synthesis of gold nanotriangles and silver nanoparticles using Aloevera plant extract. Biotechnol Prog 22:577-583

Dauthal P, Mukhopadhyay M (2016) Noble metal nanoparticles: plant-mediated synthesis, mechanistic aspects of synthesis, and applications. Ind Eng Chem Res 55:9557-9577

Dave S (2018) Electrochemical and spectral characterization of silver nanoparticles synthesized employing root extract of Curculigo orchioides. Indian J Chem Technol 25:201-207

Dawadi S, Katuwal S, Gupta A, Lamichhane U, Thapa R, Jaisi S, Parajuli N (2021) Current research on silver nanoparticles: Synthesis, characterization, and applications. J Nanomater 2021:3-23

Devi M, Devi S, Sharma V, Rana N, Bhatia R, Bhatt A (2020) Green synthesis of silver nanoparticles using methanolic fruit extract of Aegle marmelos and their antimicrobial potential against human bacterial pathogens. J Tradit Complement Med 10:158-165

Dornfeld D, Yuan C, Diaz N, Zhang T, Vijayaraghavan A (2013) Introduction to green manufacturing. In: Green manufacturing. Springer, Boston

Duan H, Wang D, Li Y (2015) Green chemistry for nanoparticle synthesis. Chem Soc Rev 44:5778-5792

Dubey M, Bhadauria S, Kushwah BS (2009) Green synthesis of nanosilver particles from extract of Eucalyptus hybrida (safeda) leaf. Dig J Nanomater Biostruct 4:537-543

Dubey S, Lahtinen M, Särkkä H, Sillanpää M (2010) Bioprospective of Sorbus aucuparia leaf extract in development of silver and gold nanocolloids. Colloids Surf B 80:26-33
Dwivedi A, Gopal K (2010) Biosynthesis of silver and gold nanoparticles using Chenopodium album leaf extract. Colloids Surf A Physicochem Eng Asp 369:27-33

Edison T, Sethuraman M (2012) Instant green synthesis of silver nanoparticles using Terminalia chebula fruit extract and evaluation of their catalytic activity on reduction of methylene blue. Process Biochem 47:1351-1357

Elemike E, Ibe K, Mbonu J, Onwudiwe D (2020) Phytonanotechnology and synthesis of silver nanoparticles. In: Phytonanotechnology. Elsevier

Elumalai E, Prasad T, Hemachandran J, Therasa S, Thirumalai T, David E (2010) Extracellular synthesis of silver nanoparticles using leaves of Euphorbia hirta and their antibacterial activities. J Pharm Sci Res 2:549-554

Espenti C, Rao K, Rao K (2016) Bio-synthesis and characterization of silver nanoparticles using Terminalia chebula leaf extract and evaluation of its antimicrobial potential. Mater Lett 174:129-133

Fischer H, Chan W (2007) Nanotoxicity: the growing need for in vivo study. Curr Opin Biotechnol 18:565-571

Gawande M, Bonifácio V, Luque R, Branco P, Varma R (2013) Benign by design: catalyst-freein-water, on-water green chemical methodologies in organic synthesis. Chem Soc Rev 42:5522-5551

Ghaedi M, Yousefinejad M, Safarpoor M, Khafri H, Purkait M (2015) Rosmarinus officinalis leaf extract mediated green synthesis of silver nanoparticles and investigation of its antimicrobial properties. J Ind Eng Chem 31:167-172

Gil-Sánchez I, Monge M, Miralles B, Armentia G, Cueva C, Crespo J, MorenoArribas M (2019) Some new findings on the potential use of biocompatible silver nanoparticles in wine making. Innov Food Sci Emerg Technol 51:64-72

Gopinath V, MubarakAli D, Priyadarshini S, Priyadharsshini NM, Thajuddin N, Velusamy P (2012) Biosynthesis of silver nanoparticles from Tribulus terrestris and its antimicrobial activity: a novel biological approach. Colloids Surf B 96:69-74

Gopinath K, Kumaraguru S, Bhakyaraj K, Mohan S, Venkatesh KS, Esakkirajan M, Arumugam A (2016) Green synthesis of silver, gold and silver/gold bimetallic nanoparticles using the Gloriosa superba leaf extract and their antibacterial and antibiofilm activities. Microb Pathog 101:1-11

Hood E (2004) Nanotechnology: looking as we leap. Environ Health Perspect 112:A740

Hussain I, Singh N, Singh A, Singh H, Singh S (2016) Green synthesis of nanoparticles and its potential application. Biotechnol Lett 38:545-560

lavicoli I, Leso V, Ricciardi W, Hodson L, Hoover M (2014) Opportunities and challenges of nanotechnology in the green economy. J Environ Health 13:1-11

Ibrahim HM (2015) Green synthesis and characterization of silvernanoparticles using banana peel extract and their antimicrobial activity against representative microorganisms. J Radiat Res Appl Sci 8:265-275

Iravani S (2011) Green synthesis of metal nanoparticles using plants. Green Chem 13:2638-2650

Iravani S, Korbekandi H, Mirmohammadi SV, Zolfaghari B (2014) Synthesis of silver nanoparticles: chemical, physical and biological methods. Res Pharm Sci 9:385

Jabir MS, Saleh YM, Sulaiman GM, Yaseen NY, Sahib UI, Dewir YH, Soliman DA (2021) Green synthesis of silver nanoparticles using Annona muricata extract as an inducer of apoptosis in cancer cells and inhibitor for NLRP3 inflammasome via enhanced autophagy. Nanomaterials 11:384

Jacob SJP, Finub JS, Narayanan A (2012) Synthesis of silver nanoparticles using Piper longum leaf extracts and its cytotoxic activity against Hep-2 cell line. Colloids Surf B 91:212-214

Jain D, Daima H, Kachhwaha S, Kothari S (2009) Synthesis of plant-mediated silver nanoparticles using papaya fruit extract and evaluation of their anti microbial activities. Dig J Nanomater Biostruct 4:557-563

Jayaseelan C, Rahuman A, Rajakumar G, Kirthi A, Santhoshkumar T, Marimuthu S, Elango G (2011) Synthesis of pediculocidal and larvicidal silver nanoparticles by leaf extract from heartleaf moonseed plant, Tinospora cordifolia Miers. Parasitol Res 109:185-194

Johnson A, Shibila T, Amutha S, Menezes IR, da Costa JG, Sampaio NF, Coutinho HD (2020) Synthesis of silver nanoparticles using Odontosoria chinensis (L.) J. Sm. and evaluation of their biological potentials. Pharmaceuticals 13:66 
Joseph S, Mathew B (2015) Microwave-assisted green synthesis of silver nanoparticles and the study on catalytic activity in the degradation of dyes. J Mol Liq 204:184-191

Kalaiarasi R, Jayallakshmi N, Venkatachalam P (2010) Phytosynthesis of nanoparticles and its applications. Plant Cell Biotechnol Mol Biol 11:1-16

Kanniah P, Radhamani J, Chelliah P, Muthusamy N, Thangapandi JJSB, E, Reeta Thangapandi J, Shanmugam R, (2020) Green synthesis of multifaceted silver nanoparticles using the flower extract of Aerva lanata and evaluation of its biological and environmental applications. Chem Sel 5:2322-2331

Karupannan S, Dowlath M, Arunachalam K (2020) Phytonanotechnology: challenges and future perspectives. In: Phytonanotechnology: challenges and prospects. Elsevier

Kavitha M, Jeyaraj S, Muthukumar P, Jeevagan A (2021) Green synthesis of silver nanoparticles using Biophytum sensitivum extract and its electrocatalytic activity towards dioxygen reduction. Mater Today Proc 47:1767-1772

Kaviya S, Santhanalakshmi J, Viswanathan B (2011) Green synthesis of silver nanoparticles using Polyalthia longifolia leaf extract along with D-sorbitol: study of antibacterial activity. J Nanotechnol 2011:1-5

Kayalvizhi T, Ravikumar S, Venkatachalam P (2016) Green synthesis of metallic silver nanoparticles using Curculigoorchioides rhizome extracts and evaluation of its antibacterial, larvicidal, and anticancer activity. J Environ Eng 142:C4016002

Khan SH (2020) Green nanotechnology for the environment and sustainable development. In: Green materials for wastewater treatment. Environmental chemistry for a sustainable world. Springer, Cham

Khanra K, Panja S, Choudhuri I, Chakraborty A, Bhattacharyya N (2016) Bactericidal and cytotoxic properties of silver nanoparticle synthesized from root extract of Asparagus Racemosus. Nano Biomed Eng 8:39-46

Kharissova O, Dias H, Kharisov B, Pérez B, Pérez V (2013) The greener synthesis of nanoparticles. Trends Biotechnol 31:240-248

Khatoon N, Mazumder J, Sardar M (2017) Biotechnological applications of green synthesized silver nanoparticles. J Nanosci Curr Res 2:107

Kim J, Rheem Y, Yoo B, Chong Y, Bozhilov K, Kim D, Myung N (2010) Peptidemediated shape-and size-tunable synthesis of gold nanostructures. Acta Biomater 6:2681-2689

Kim BS, Song JY (2010) Biological synthesis of gold and silver nanoparticles using plant leaf extracts and antimicrobial applications. In: Biocatalysis and biomolecular engineering, pp 447-457

Klaus T, Joerger R, Olsson E, Granqvist C (1999) Silver-based crystalline nanoparticles, microbially fabricated. Proc Natl Acad Sci 96:13611-13614

Kotakadi V, Rao Y, Gaddam S, Prasad T, Reddy A, Gopal D (2013) Simple and rapid biosynthesis of stable silver nanoparticles using dried leaves of Catharanthus roseus Linn. G. Donn and its anti microbial activity. Colloids Surf B 105:194-198

Kumar P, Pammi S, Kollu P, Satyanarayana K, Shameem U (2014) Green synthesis and characterization of silver nanoparticles using Boerhaavia diffusa plant extract and their anti bacterial activity. Ind Crops Prod 52:562-566

Kumar S, Lather V, Pandita D (2015) Green synthesis of therapeutic nanoparticles: an expanding horizon. Nanomedicine 10:2451-2471

Lade B, Shanware A (2020) Phytonanofabrication: methodology and factors affecting biosynthesis of nanoparticles. In: Smart nanosystems for biomedicine, optoelectronics and catalysis. IntechOpen, London.

Lade BD, Shanware AS (2020) Phytonanofabrication: methodology and factors affecting biosynthesis of nanoparticles. In: Nanosystems. IntechOpen, London, pp 1-17

Lade B, Patil A (2017) Silver nano fabrication using leaf disc of Passiflora foetida Linn. Appl Nanosci 7:181-192

Latha M, Sumathi M, Manikandan R, Arumugam A, Prabhu N (2015) BiocataIytic and antibacterial visualization of green synthesized silver nanoparticles using Hemidesmus indicus. Microbial Pathog 82:43-49

Lokina S, Stephen V (2011) Synthesis of silver nanoparticles using Cynodondactylon plant extract and evaluation of their antimicrobial activities and cytotoxicity. In: International conference on green technology and environmental conservation (GTEC-2011)

Majeed A, Ullah W, Anwar A, Shuaib A, Ilyas U, Khalid P, Ali S (2018) Cost- effective biosynthesis of silver nanoparticles using different organs of plants and their antimicrobial applications: a review. Mater Technol 33:313-320
Makarov V, Love A, Sinitsyna O, Makarova S, Yaminsky I, Taliansky M, Kalinina N (2014) "Green" nanotechnologies: synthesis of metal nanoparticles using plants. Acta Nat 6:35-44

Malik P, Shankar R, Malik V, Sharma N, Mukherjee T (2014) Green chemistry based benign routes for nanoparticle synthesis. J Nanopart 2014:1-14

Maniam G, Govindan N, Rahim M, Yusoff M (2020) Plant extracts: nanoparticle sources. In: Phytonanotechnology challenges and prospects. Elsevier

Michiels J, Kevers C, Pincemail J, Defraigne J, Dommes J (2012) Extraction conditions can greatly influence antioxidant capacity assays in plant food matrices. Food Chem 130:986-993

Mittal A, Kaler A, Banerjee U (2012) Free radical scavenging and antioxidant activity of silver nanoparticles synthesized from flower extract of Rhododendron dauricum. Nano Biomed Eng 4:118-124

Mohamad NAN, Arham NA, Jai J, Hadi A (2014) Plant extract as reducing agent in synthesis of metallic nanoparticles: a review. In: Advanced materials research, Trans Tech Publications Ltd

Mohapatra B, Kuriakose S, Mohapatra S (2015) Rapid green synthesis of silver nanoparticles and nanorods using Piper nigrum extract. J Alloys Compd 637:119-126

Murugan K, Labeeba MA, Panneerselvam C, Dinesh D, Suresh U, Subramaniam J, Benelli G (2015) Aristolochia indica green-synthesized silver nanoparticles: a sustainable control tool against the malaria vector Anopheles stephensi? Res Vet Sci 102:127-135

Naidu S, Sawhney R, Li X (2008) A methodology for evaluation and selection of nanoparticle manufacturing processes based on sustainability metrics. Environ Sci Technol 42:6697-6702

Nakkala J, Mata R, Gupta A, Sadras S (2014) Biological activities of green silver nanoparticles synthesized with Acorous calamus rhizome extract. Eur $J$ Med Chem 85:784-794

Narayanan K, Sakthivel N (2011a) Extracellular synthesis of silver nanoparticles using the leaf extract of Coleus amboinicus Lour. Mater Res Bull 46:1708-1713

Narayanan K, Sakthivel N (201 1b) Green synthesis of biogenic metal nanoparticles by terrestrial and aquatic phototrophic and heterotrophic eukaryotes and biocompatible agents. Adv Colloid Interface Sci 169:59-79

Narayanan K, Sakthivel N (2011c) Synthesis and characterization of nano-gold composite using Cylindrocladium floridanum and its heterogeneous catalysis in the degradation of 4-nitrophenol. J Hazard Mater 189:519-525

Nasrollahzadeh M, Sajadi S, Issaabadi Z, Sajjadi M (2019) Biological sources used in green nanotechnology. In: Interface science and technology. Elsevier

Nasrollahzadeh M, Sajjadi M, Sajadi S, Issaabadi Z (2019) Green nanotechnology. In: Interface science and technology. Elsevier

Nayak D, Pradhan S, Ashe S, Rauta P, Nayak B (2015) Biologically synthesised silver nanoparticles from three diverse family of plant extracts and their anticancer activity against epidermoid A431 carcinoma. J Colloid Interface Sci 457:329-338

Nishino T, Fukuda A, Nagumo T, Fujihara M, Kaji E (1999) Inhibition of the generation of thrombin and factor Xa by a fucoidan from the brown seaweed Ecklonia kurome. Thromb Res 96:37-49

Pankhurst QA, Connolly J, Jones S, Dobson J (2003) Applications of magnetic nanoparticles in biomedicine. J Phys D Appl Phys 36:R167

Parial D, Pal R (2015) Biosynthesis of monodisperse gold nanoparticles by green alga Rhizoclonium and associated biochemical changes. J Appl Phycol 27:975-984

Park Y (2014) A new paradigm shift for the green synthesis of antibacterial silver nanoparticles utilizing plant extracts. Toxicol Res 30:169-178

Patil S, Chaudhari G, Paradeshi J, Mahajan R, Chaudhari BL (2017) Instant green synthesis of silver-based herbo-metallic colloidal nanosuspension in Terminalia bellirica fruit aqueous extract for catalytic and antibacterial applications. 3 Biotech 7:36

Prathap M, Alagesan A, Kumari B (2014) Anti-bacterial activities of silver nanoparticles synthesized from plant leaf extract of Abutilon indicum (L.) Sweet. J Nanostruct Chem 4:106

Premasudha P, Venkataramana M, Abirami M, Vanathi P, Krishna K, Rajendran R (2015) Biological synthesis and characterization of silver nanoparticles using Eclipta alba leaf extract and evaluation of its cytotoxic and antimicrobial potential. Bull Mater Sci 38:965-973

Raghunandan D, Mahesh B, Basavaraja S, Balaji S, Manjunath S, Venkataraman A (2011) Microwave-assisted rapid extracellular synthesis of 
stable bio-functionalized silver nanoparticles from guava (Psidium guajava) leaf extract. J Nanopart Res 13:2021-2028

Rai M, Yadav A (2013) Plants as potential synthesiser of precious metal nanoparticles: progress and prospects. IET Nanobiotechnol 7:117-124

Rajakumar G, Rahuman A, Roopan S, Khanna V, Elango G, Kamaraj C, Velayutham K (2012) Fungus-mediated biosynthesis and characterization of $\mathrm{TiO}_{2}$ nanoparticles and their activity against pathogenic bacteria. Spectrochim Acta A Mol Biomol Spectrosc 91:23-29

Rajaram K, Aiswarya DC, Sureshkumar P (2015) Green synthesis of silver nanoparticle using Tephrosia tinctoria and its antidiabetic activity. Mater Lett 138:251-254

Rajkuberan C, Sudha K, Sathishkumar G, Sivaramakrishnan S (2015) Antibacterial and cytotoxic potential of silver nanoparticles synthesized using latex of Calotropis gigantea L. Spectrochim Acta A Mol Biomol Spectrosc 136:924-930

Ramaswamy U, Mukundan D, Sreekumar A, Mani V (2015) Green synthesis and characterization of silver nanoparticles using aqueous whole plant extract of Vernonia cinerea L. and its biological activities. Mater Today Proc 2:4600-4608

Ramya M, Subapriya M (2012) Green synthesis of silver nanoparticles. Int J Pharma Med Biol Sci 1:54-61

Ranjani S, Tamanna K, Hemalatha S (2019) Triphala green nano colloids: synthesis, characterization and screening biomarkers. Appl Nanosci 10:1269-1279

Rao KJ, Paria S (2013) Green synthesis of silver nanoparticles from aqueous Aegle marmelos leaf extract. Mater Res Bull 48:628-634

Rastogi L, Arunachalam J (2011) Sunlight based irradiation strategy for rapid green synthesis of highly stable silver nanoparticles using aqueous garlic (Allium sativum) extract and their antibacterial potential. Mater Chem Phys 129:558-563

Raveendran P, Fu J, Wallen SL (2003) Completely "green" synthesis and stabilization of metal nanoparticles. J Am Chem Soc 125:13940-13941

Reddy GAK, Joy JM, Mitra T, Shabnam S, Shilpa T (2012) Nano silver-a review. Int J Adv Pharm Sci 2:09-15

Remya VR, Abitha VK, Rajput PS, Rane AV, Dutta A (2017) Silver nanoparticles green synthesis: a mini review. Chem Int 3:165-171

Renuka R, Devi KR, Sivakami M, Thilagavathi T, Uthrakumar R, Kaviyarasu K (2020) Biosynthesis of silver nanoparticles using Phyllanthus emblica fruit extract for antimicrobial application. Biocatal Agric Biotechnol 24:101567

Rout A, Jena P, Parida U, Bindhani B (2013) Green synthesis of silver nanoparticles using leaves extract of Centella asiatica L. For studies against human pathogens. Int J Pharma Bio Sci 4:661-674

Sadeghi B, Rostami A, Momeni S (2015) Facile green synthesis of silver nanoparticles using seed aqueous extract of Pistacia atlantica and its antibacterial activity. Spectrochim Acta A Mol Biomol Spectrosc 134:326-332

Safaepour M, Shahverdi A, Shahverdi H, Khorramizadeh M, Gohari A (2009) Green synthesis of small silver nanoparticles using geraniol and its cytotoxicity against fibrosarcoma-wehi 164. Avicenna J Med Biotechnol 1:111

Saha N, Trivedi P, Gupta S (2016) Surface plasmon resonance (SPR) based optimization of biosynthesis of silver nanoparticles from rhizome extract of Curculigo orchioides Gaertn. and its antioxidant potential. J Clust Sci 27:1893-1912

Sahayaraj K, Roobadevi M, Rajesh S, Azizi S (2015) Vernonia cinerea (L.) Less. silver nanocomposite and its antibacterial activity against a cotton pathogen. Res Chem Intermed 41:5495-5507

Sahu N, Soni D, Chandrashekhar B, Sarangi B, Satpute D, Pandey R (2013) Synthesis and characterization of silver nanoparticles using Cynodon dactylon leaves and assessment of their antibacterial activity. Bioprocess Biosyst Eng 36:999-1004

Sajjad S, Leghari SAK, Ryma NUA, Farooqi SA (2018) Green synthesis of metal-based nanoparticles and their applications. In: Green metal nanoparticles: synthesis, characterization and their applications. Scrivener Publishing LLC, Wiley

Sangeetha G, Rajeshwari S, Venckatesh R (2011) Green synthesis of zinc oxide nanoparticles by Aloe barbadensis miller leaf extract: Structure and optical properties. Mater Res Bull 46:2560-2566
Sankar R, Rizwana K, Shivashangari K, Ravikumar V (2015) Ultra-rapid photocatalytic activity of Azadirachta indica engineered colloidal titanium dioxide nanoparticles. Appl Nanosci 5:731-736

Sathishkumar M, Sneha K, Won S, Cho C, Kim S, Yun Y (2009) Cinnamon zeylanicum bark extract and powder mediated green synthesis of nano-crystalline silver particles and its bactericidal activity. Colloids Surf B 73:332-338

Satyanarayana B, Reddy N, Rao J (2020) Biogenesis of silver nanoparticles using leaf extracts of Asparagus racemosus and Sophora interrupta: structure characterization, antibacterial and anticancer studies. SN Appl Sci 2:1-15

Schmidt K (2007) Green nanotechnology: it's easier than you think. Project on Emerging Nanotechnologies, Woodrow Wilson International Center of Scholars, Washington, DC

Selvam K, Sudhakar C, Govarthanan M, Thiyagarajan P, Sengottaiyan A, Senthilkumar B, Selvankumar T (2017) Eco-friendly biosynthesis and characterization of silver nanoparticles using Tinospora cordifolia (Thunb.) Miers and evaluate its antibacterial, antioxidant potential. J Radiat Res Appl Sci 10:6-12

Shankar S, Rai A, Ahmad A, Sastry M (2004) Rapid synthesis of Au, Ag, and bimetallic Au core-Ag shell nanoparticles using Neem (Azadirachta indica) leaf broth. J Colloid Interf Sci 275:496-502

Shankar S, Jaiswal L, Aparna R, Prasad R (2014) Synthesis, characterization, in vitro biocompatibility, and antimicrobial activity of gold, silver and gold silver alloy nanoparticles prepared from Lansium domesticum fruit peel extract. Mater Lett 137:75-78

Sharma R (2021) Synthesis of Terminalia bellirica fruit extract mediated silver nanoparticles and application in photocatalytic degradation of wastewater from textile industries. Mater Today Proc 44:1995-1998

Shekhawat MS, Manokari M, Kannan N, Revathi J, Latha R (2013) Synthesis of silver nanoparticles using Cardiospermum halicacabum L. leaf extract and their characterization. J Phytopharm 2:15-20

Shetty P, Supraja N, Garud M, Prasad T (2014) Synthesis, characterization and antimicrobial activity of Alstonia scholaris bark-extract-mediated silver nanoparticles. J Nanostructure Chem 4:161-170

Si S, Mandal T (2007) Tryptophan-based peptides to synthesize gold and silver nanoparticles: a mechanistic and kinetic study. Chem Eur J 13:3160-3168

Singh C, Sharma V, Naik P, Khandelwal V, Singh H (2011) A green biogenic approach for synthesis of gold and silver nanoparticles using Zingiber officinale. Dig J Nanomater Biostruct 6:535-542

Sivakumar M, Surendar S, Jayakumar M, Seedevi P, Sivasankar P, Ravikumar M, Loganathan S (2020) Parthenium hysterophorus mediated synthesis of silver nanoparticles and its evaluation of antibacterial and antineoplastic activity to combat liver cancer cells. J Clust Sci 32:167-177

Sivaraman SK, Elango I, Kumar S, Santhanam V (2009) A green protocol for room temperature synthesis of silver nanoparticles in seconds. Curr Sci 00113891(97):1055-1059

Suma CS, Navyashree HT (2018) Synthesis and characterization of silver nanoparticle from Emilia Sonchifolia (L) leaf extract and their antibacterial assay. Int J Recent Sci Res 9:28280-28283

Suman T, Rajasree S, Kanchana A, Elizabeth S (2013) Biosynthesis, characterization and cytotoxic effect of plant mediated silver nanoparticles using Morinda citrifolia root extract. Colloids Surf B 106:74-78

Sun Y, Mayers B, Herricks T, Xia Y (2003) Polyol synthesis of uniform silver nanowires: a plausible growth mechanism and the supporting evidence. Nano Lett 3:955-960

Sundararajan B, Mahendran G, Thamaraiselvi R, Kumari B (2016) Biological activities of synthesized silver nanoparticles from Cardiospermum halicacabum L. Bull Mater Sci 39:423-431

Supraja S, Ali SM, Chakravarthy N, Jaya Prakash Priya A, Sagadevan E, Kasinathan MK, Arumugam P (2013) Green synthesis of silver nanoparticles from Cynodon dactylon leaf extract. Int J Chem Tech Res 5:271-277

Tanase C, Berta L, Mare A, Man A, Talmaciu Al, Roșca I, Popa VI (2020) Biosynthesis of silver nanoparticles using aqueous bark extract of Picea abies $L$. and their antibacterial activity. Eur J Wood Wood Prod 78:281-291

Tiwari P, Kumar B, Kaur M, Kaur G, Kaur H (2011) Phytochemical screening and extraction: a review. Int Pharma Sci 1:98-106

Tripathy A, Raichur A, Chandrasekaran N, Prathna T, Mukherjee A (2010) Process variables in biomimetic synthesis of silver nanoparticles by 
aqueous extract of Azadirachta indica (Neem) leaves. J Nanopart Res 12:237-246

Uzunuigbe EO, Kappo AP, Mlowe S, Revaprasadu N (2020) Bioinspired Synthesis of Acacia senegal leaf extract functionalized silver nanoparticles and its antimicrobial evaluation. J Nanomater. https://doi.org/10.1155/2020/ 6474913

Varadavenkatesan T, Selvaraj R, Vinayagam R (2016) Phyto-synthesis of silver nanoparticles from Mussaenda erythrophylla leaf extract and their application in catalytic degradation of methyl orange dye. J Mol Liq 221:1063-1070

Varghese KJ, Anila J, Nagalekshmi R, Resiya S, Sonu J (2010) Dasapushpam: the traditional uses and the therapeutic potential of ten sacred plants of Kerala state in India. Int J Pharmal Sci Res 1:50

Venkatachalam P, Kayalvizhi T, Udayabanu J, Benelli G, Geetha N (2017) Enhanced antibacterial and cytotoxic activity of phytochemical loadedsilver nanoparticles using Curculigo orchioides leaf extracts with different extraction techniques. J Clust Sci 28:607-619

Verma A, Mehata MS (2016) Controllable synthesis of silver nanoparticles using neem leaves and their antimicrobial activity. J Radiat Res Appl Sci 9:109-115

Verma A, Gautam SP, Bansal KK, Prabhakar N, Rosenholm JM (2019) Green nanotechnology: advancement in phytoformulation research. Medicines 6:39

Vijayakumar M (2013) Biosynthesis, characterisation and anti-bacterial effect of plant-mediated silver nanoparticles using Artemisia nilagirica. Ind Crop Prod 41:235-240

Wang C, Mathiyalagan R, Kim Y, Castro-Aceituno V, Singh P, Ahn S, Yang D (2016a) Rapid green synthesis of silver and gold nanoparticles using Dendropanax morbifera leaf extract and their anticancer activities. Int $J$ Nanomed 11:3691

Wang P, Lombi E, Zhao F, Kopittke P (2016b) Nanotechnology: a new opportunity in plant sciences. Trend Plant Sci 21:699-712

Xu ZP, Zeng QH, Lu GQ, Yu AB (2006) Inorganic nanoparticles as carriers for efficient cellular delivery. Chem Eng Sci 61:1027-1040

Yoshida Jl, Kim H, Nagaki A (2011) Green and sustainable chemical synthesis using flow microreactors. Chemsuschem 4:331-340

Yu CH, Chen J, Xiong YK, Li X, Dai X, Shi C (2012) Optimization of multi-stage countercurrent extraction of antioxidants from Ginkgo biloba L. leaves. Food Bioprod Process 90:95-101

Zani M, Ahmad H, Razak A (2016) Synthesis and characterisation of silver nanoparticles using Vernonia Cinerea aqueous extract and their cytotoxicity activity against kasumi-1 cell line. J Teknol 78:57-65

\section{Publisher's Note}

Springer Nature remains neutral with regard to jurisdictional claims in published maps and institutional affiliations.

\section{Submit your manuscript to a SpringerOpen ${ }^{\circ}$ journal and benefit from:}

- Convenient online submission

- Rigorous peer review

- Open access: articles freely available online

- High visibility within the field

- Retaining the copyright to your article

Submit your next manuscript at $\boldsymbol{\nabla}$ springeropen.com 